\title{
The Salford Lung Study: a pioneering comparative effectiveness approach to COPD and asthma in clinical trials
}

This article was published in the following Dove Press journal:

Pragmatic and Observational Research

20 September 2017

Number of times this article has been viewed

\author{
Timothy E Albertson ${ }^{1-3}$ \\ Susan Murin ${ }^{1,2}$ \\ Mark E Sutter ${ }^{2,3}$ \\ James A Chenoweth ${ }^{2,3}$ \\ 'Department of Internal Medicine, \\ Division of Pulmonary, Critical \\ Care and Sleep Medicine, School of \\ Medicine, University of California, \\ Davis, Sacramento, ${ }^{2}$ Department of \\ Medicine, Veterans Administration \\ Northern California Healthcare \\ System, Mather, ${ }^{3}$ Department of \\ Emergency Medicine, School of \\ Medicine, University of California, \\ Davis, Sacramento, CA, USA
}

\begin{abstract}
The Salford Lung Study (SLS) of patients with asthma and chronic obstructive pulmonary disease (COPD) is a practical, community-based, randomized, open-label pragmatic study on the efficacy and safety of the once-daily dry powder inhaler that combines the inhaled corticosteroid fluticasone furoate (FF) with the long-acting beta ${ }_{2}$ agonist vilanterol (VI). The asthma component of the SLS is not yet reported but the COPD component, done over a 12-month period, found a statistically significant $8.4 \%$ reduction in COPD exacerbations when compared to usual care. No differences in adverse events, including serious adverse events and pneumonia, were noted. The importance of real-world findings, such as those found in the SLS COPD trial with inhaled FF/VI, is discussed in comparison to classical randomized controlled trials (RCTs) with inhaled FF/VI in COPD patients. The real-world, community-based pragmatic RCT like the SLS provides additional generalizable data with direct clinical applicability and potential usefulness in the development of practice guidelines. The results from the SLS, along with those of large and small RCTs, are supportive of the use of once-daily FF/VI in COPD maintenance therapy.
\end{abstract}

Keywords: Salford Lung Study, pragmatic randomized controlled trials, asthma, COPD, fluticasone furoate, FF, vilanterol, VI, COPD exacerbations

\section{Introduction and limitations of the randomized controlled trial}

The last 50 years has seen an amazing increase in the number of therapeutic agents available to the clinician. During this period, the anchor to proving the initial efficacy and safety of a new drug has been the randomized controlled trial (RCT). The RCT attempts to reduce variability between groups, decrease confounders, and insure equipoise resulting in the need for smaller sample size to show a positive drug effect. However, smaller sample size makes the detection of rare side effects less likely.

Two examples of the potential limitations of relying solely on RCTs for safety and efficacy determinations are reviewed. In the late 1950s, thalidomide was approved in Europe as a nonaddictive and nonbarbiturate sedative/hypnotic agent. It quickly became one of the top-selling drugs worldwide, gaining approval in 46 countries, not including the United States. Its effectiveness and safety were emphasized and it was also found to have efficacy as an antiemetic in pregnancy. ${ }^{1}$ Thalidomide was eventually banned in late 1961 after two investigators - Lenz in Germany, and McBride in Australia noted congenital birth defects associated with its use. Increased miscarriages and over 10,000 children with severe birth defects were reported. ${ }^{1}$ Lack of appropriate preclinical
Correspondence: Timothy E Albertson Department of Internal Medicine, Davis School of Medicine, University of California, 4I50 V Street, Suite 3100, Sacramento, CA 95817, USA Email tealbertson@ucdavis.edu 
teratogenic testing, limited number and size of RCTs, a shift in clinical indications resulting in the use of thalidomide in pregnant patients, and the lack of real-world testing put large numbers of patients and fetuses at risk with this drug. A second example is the use of the appetite-suppressant or anorectic agents fenfluramine, dexfenfluramine, or combinations of these drugs with phentermine (often called "fen/ phen"). ${ }^{2}$ These drugs were shown in RCTs to have efficacy in reducing weight in obese patients, but only later epidemiological and observational studies generated by initial case reports found a strong association between their use and both cardiac valvular abnormalities ${ }^{3-6}$ and pulmonary hypertension. ${ }^{7,8}$ Perhaps, instead of just more or larger RCTs, more real-world experience and analysis before and at the time of drug approval would have detected these problematic side effects earlier, even before the release of the drug.

The daily use of vitamin $\mathrm{K}$ antagonists offers another example of the potential variability seen between RCTs and real-world rates of medication adherence. A study of Ohio Medicaid patients with new-onset nonvalvular atrial fibrillation (AF) found only $9.7 \%$ of all patients and $11.9 \%$ without contraindications filled a warfarin prescription 7 days before to 30 days after the new AF diagnosis. ${ }^{9}$ This study does not necessarily reflect adherence, as the number of the 11,699 patients who were advised to go on vitamin $\mathrm{K}$ antagonist anticoagulants or were actually prescribed them was not known. In another study, a large clinical trial of 18,113 patients with AF studied dabigatran versus warfarin and found the mean percentage of time that patients on warfarin had an international normalized ratio (INR) within the therapeutic range (2.0-3.0) was $64 \% .{ }^{10} \mathrm{~A}$ meta-analysis evaluating both retrospective and prospective trials assessing the quality of warfarin control in patients with atrial fibrillation in the United States found that patients spent a mean 55\% (95\% confidence interval [CI], CI $51 \%-58 \%$ ) of the time in therapeutic INR range. ${ }^{11}$ Warfarin use adherence was prospectively studied in a real-world setting in two anticoagulation clinics serving 22,425 patients. ${ }^{12}$ The authors found warfarin nonadherence was common $(21 \%$ of patient-days observed.). A number of risk factors for warfarin nonadherence including younger age, male sex, lower stroke risk, poor cognitive function, poverty, and higher education attainment (beyond high school) have been identified. ${ }^{12,13}$ Drug adherence is an important variable and can affect the actual efficacy of a drug when used in a real-world setting.

The RCT may have higher drug adherence rates than would be seen in real-world use because the drug is provided, and a kind of "Hawthorne Effect" could occur with the constant encouragement of investigators and research staff. The Hawthorne Effect can be seen in RCTs when the inhaled placebo-treated group shows significant improvement in forced expiratory volume in one second (FEV), after treatment that is still statistically less than the improvement seen in the "active" drug-treated group. This improvement has been suggested to be the result of factors like psychologist support, better adherence to concurrent medications, and better control of comorbid conditions. ${ }^{14} \mathrm{~A}$ recent observed trial on hand washing has quantified the Hawthorne Effect. ${ }^{15}$ Therapeutic use of the Hawthorne Effect has been advocated in the treatment of chronic obstructive pulmonary disease (COPD). ${ }^{14}$ Trial participants can experience the Hawthorne Effect in an RCT when there is a "change in the trial's participants' outcome attributable to the awareness of being in a research study." 16 This can reduce the generalizability of the RCT results to "real-world" health care settings.

The RCT is a well-controlled efficacy or explanatory trial designed to determine, under experimental conditions, whether an intervention such as a drug produces a reproducible result under optimal conditions. ${ }^{17,18}$ In contrast, the pragmatic RCT (pRCT) is a type of effectiveness or pragmatic trial that measures the potential beneficial result of an intervention such as a drug in real-world conditions. ${ }^{17,18}$ When an intervention or drug is tested in both an RCT (efficacy) and a pRT (effectiveness), the intervention is being evaluated in a pragmatic-explanatory continuum that expands the potential generalizability of a positive response. ${ }^{19}$

The average total cost of developing a new drug from preclinical discovery, through clinical trials with one or more RCTs, to gaining market approval is estimated to be a staggering $\$ 2.5$ billion. ${ }^{20}$ Despite successes, the number of new drugs approved by the US Food and Drug Administration per inflation-adjusted billion US dollars spent on drug development has fallen dramatically from 1950 to $2010 .^{21}$

The need to get more relevant clinical drug data and yet not make the clinical drug development phase even more expensive has led to a call for considering changing from a Bayesian RCT model that uses a fixed design to an adaptive design. ${ }^{21,22}$ The "adaptive trial design" used in phase 3 trials allows changes in some important trial design features during the trial after unblinded data analysis has occurred and, thus, still controlling the overall Type I error level. ${ }^{21}$ Another approach is to get real-world data by retrospective analysis of multiple large RCTs or epidemiological approaches in patients taking the drug after approval. These approaches can often allow detection of rare side effects, drug use adherence, and frequency of specific drug use or usage patterns. ${ }^{23}$ Real-world data such as that from a pRCT can be seen as 
another layer of effectiveness data - not replacing the RCT or efficacy data but rather providing a more comprehensive evaluation of a drug. Real-world observational studies prior to or after drug approval can also help address efficacy and side effects including potential disease-drug and drug-drug interactions. ${ }^{24}$ If designed correctly, they can evaluate drug-use adherence and provide a comprehensive side effect profile.

The double-blind RCT is designed to show efficacy and causal relationship between test agent and outcome in a defined population. It attempts to minimize or balance comorbidities and confounders, and insure equipoise. The well-run RCT insures a high level of test agent adherence and is considered the most robust form of medical evidence. ${ }^{25}$ A pRCT like the Salford Lung Study (SLS)-COPD or -asthma trials evaluates a therapy in a "real-world" setting with drug-use adherence rates, side effects, comorbidities, and effectiveness that reflect use in a real population. By integrating multiple data sources including the common area electronic medical record (EMR), both safety and effectiveness data can be obtained. ${ }^{26,27}$

\section{The real-world Salford Lung Study}

The SLS comprises two phase 3 real-world pragmatic randomized trials evaluating once-daily inhaled fluticasone furoate (FF) combined with vilanterol (VI) in patients with COPD or asthma in and around the city of Salford, United Kingdom. ${ }^{25,28}$ The Salford COPD trial has also been called an open-label phase $3 \mathrm{RCT}$. It evaluated once-daily inhaled FF/ VI compared to usual care for up to 54 weeks for the primary outcome of moderate to severe COPD exacerbations. ${ }^{16}$ The Salford area has a high prevalence of COPD and an established EMR that connects the single hospital in the area with primary and secondary community-care providers. ${ }^{28}$ Local pharmacists collaborated to insure patients were able to get their usual and study medications in local pharmacies. This feature of the SLS trial adds to its real-world characteristics. Both the SLS-COPD and the SLS-asthma trials studied prelicensed, once-daily, inhaled powder FF combined with VI in a 12-month open-label, phase 3, pRCT, monitoring both safety and effectiveness. ${ }^{26}$

\section{The Salford Lung Study-Asthma}

The dry-powder once-daily inhaler of FF/VI combines an inhaled corticosteroid (ICS) with enhanced-affinity glucocorticoid receptor agonism and potent anti-inflammatory effects with a long-acting beta ${ }_{2}$-adrenergic agonist (LABA). It is available in two concentrations including FF/VI at 100/25 or 200/25 mcg, both dosed once-daily. It is approved for the treatment of asthma in England, Europe, and Japan under the trade name of Relvar $\AA$ Ellipta $\AA$, and in the United States as Breo ${ }^{\circledR}$ Ellipta. ${ }^{29-31}$ Extensive reviews have summarized data from multiple RCTs supporting the use of inhaled dry-powder $\mathrm{FF} / \mathrm{VI}$ as a maintenance treatment in asthmatic patients not controlled on an ICS alone. ${ }^{29-32}$ A detailed review of the multiple pharmacodynamic and pharmacokinetic assessments of inhaled FF/VI in the treatment of asthma is also available. ${ }^{33} \mathrm{~A}$ recent Cochrane systematic review of 14 RCTs with inhaled FF/VI in asthma patients included a combined 5,638 patients who finished the various trials. The analysis concluded there was "some evidence" suggesting a clear advantage for inhaled $\mathrm{FF} / \mathrm{VI}$ compared to placebo in improving $\mathrm{FEV}_{1}$ and in peak expiratory flow measurements. ${ }^{34}$ Only two trials included asthma exacerbations as a study endpoint or outcome variable with FF/VI and, since no exacerbations were reported in either treatment arm, no conclusions could be drawn. No major or significant adverse events were seen with inhaled $\mathrm{FF} / \mathrm{VI}$ in this review. ${ }^{34}$

The SLS-Asthma trial evaluates open-label, once-daily FF (100 or $200 \mathrm{mcg}$ ) combined with VI $(25 \mathrm{mcg})$ in the combined dry-powder inhaler (Revlar ${ }^{\circledR}$ Ellipta ${ }^{\circledR}$ ) versus existing asthma maintenance therapy using a pRCT design. ${ }^{35}$ As the study was started before licensing, it was an investigational drug study conducted in a real-world clinical setting designed to consider drug-use adherence, comorbidities, polypharmacy, and real-world factors on drug use, effectiveness, and safety. The primary endpoint includes an Asthma Control Test at Week 24 with safety endpoints that include the incidence and time to first serious adverse events, such as the incidence of serious pneumonias. ${ }^{35}$ Data monitoring utilizes the Salford integrated EMR, allowing near real-time collection of safety and efficacy data. This pRCT is a complement to the standard RCTs with inhaled FF/VI in the maintenance treatment for asthma patients. Since this study compares the combination FF/VI inhaler against standard therapy (not placebo), it provides a relevant comparison. Data on this pRCT are anticipated soon, as the results from a similar SLS study in COPD patients were released in September 2016. ${ }^{36}$

\section{The Salford Lung Study-COPD}

The second phase 3 component of the SLS is a real-world pRCT of inhaled FF/VI in patients with COPD who were $\geq 40$ years old and had had at least one COPD exacerbation in the previous 3 years. The patients were randomized 1:1 to open-labeled inhaled FF/VI (100/25 mcg) once-daily versus continuing their existing therapy. ${ }^{28}$ The COPD phase 3 SLS study initially aimed to randomize 7,000 patients in the yearlong, open-label study of once-daily FF/VI (100/25 mcg), 
compared to continuing existing therapy in a real-world setting. ${ }^{25}$ Using their Salford EMR, a total of 4,478 COPD patients were identified by historical diagnosis from a general practitioner. They had to be taking one or more long-acting bronchodilator, ICS, or combination inhalers, with $55 \%$ on ICS/LABA and $36 \%$ on long-acting muscarinic antagonist (LAMA) at baseline. ${ }^{27,36}$ The phase 3 pRCT SLS-COPD study ended up assigning 2,799 patients with a history of at least one exacerbation of COPD (eCOPD) in the 3 years prior to enrollment to treatment groups. Patients randomized to $\mathrm{FF}$ / VI had to stop any pre-randomization LABA use, but those on a combination LABA/LAMA were allowed to continue an inhaled LAMA with the daily FF/VI. ${ }^{36}$ Patients were recruited between March 13, 2012 and October 23, 2014. No restrictions regarding past or current smoking history, $\mathrm{FEV}_{1}$, or other spirometry values were imposed. ${ }^{36} \mathrm{~A}$ moderate eCOPD was defined as the subject receiving an exacerbationrelated prescription for oral corticosteroids and/or antibiotics, whereas a severe eCOPD was an exacerbation requiring hospitalization. ${ }^{37}$ Statistical analysis of subgroups took into account baseline medication, lung function comorbidities, and other factors. ${ }^{28}$

Some have questioned whether the Salford Lung COPD Study was really a pragmatic RCT, assessing it using the nine domains of the PRECIS-2 tool. Using this tool, Dal-Ré concluded there was a mix of both explanatory and pragmatic domains represented in the clinical trial. ${ }^{16}$

The rate of moderate or severe COPD exacerbations during the SLS-COPD study period was 1.74 per year for the FF/VI group and 1.90 per year for the usual care group. This was an $8.4 \%$ reduction in exacerbations in the FF/VI group (95\% CI 1.1-15.2, $P=0.02$ ). No difference in time to the first moderate to severe eCOPD between the FF/VI-treated and usual care group was seen. Also, no difference was seen between the FF/VI-treated group and usual care group in the annual rate of COPD-related visits with primary care providers (FF/VI group $1.7 \%$ lower; 95\% CI 5.1\%-8.0\%). The rates of serious adverse events (SAE) were similar between the groups with 404 patients (29\%) in the FF/VI-treated group and 383 patients $(27 \%)$ in the usual care group manifesting a SAE. ${ }^{36}$ Table 1 summarizes the SAEs reported in this trial. When pneumonia was evaluated, 94 patients (7\%) of the FF/VI group had pneumonia one or more times, as did 83 $(6 \%)$ of the usual group (incidence ratio $[\mathrm{IR}]=1.1,95 \% \mathrm{CI}$ 0.9-1.5). Pneumonia with a fatal outcome was reported in 13 patients $(1 \%)$ in each group.

The reduction in COPD exacerbations as seen in this pRCT trial was similarly found in several smaller RCT stud-
Table I Serious adverse events in the Salford-COPD pRCT

\begin{tabular}{|c|c|c|}
\hline Event & $\begin{array}{l}\text { FF/VI } \\
(N=I, 396) \\
N(\%)\end{array}$ & $\begin{array}{l}\text { Usual Care } \\
(\mathrm{N}=1,403) \\
\mathrm{N}(\%)\end{array}$ \\
\hline \multicolumn{3}{|l|}{ Cardiovascular SAE } \\
\hline Any event & $108(8)$ & $107(8)$ \\
\hline Arrhythmia & $52(4)$ & $54(4)$ \\
\hline Heart failure & $28(2)$ & $28(2)$ \\
\hline Cardiac ischemia & $34(2)$ & $33(2)$ \\
\hline Hypertension & 0 & $\mathrm{I}(<\mathrm{I})$ \\
\hline Stroke & $21(2)$ & $25(2)$ \\
\hline \multicolumn{3}{|l|}{ Respiratory SAE } \\
\hline Pneumonia & $94(7)$ & $83(6)$ \\
\hline Lower respiratory tract infection & $64(5)$ & $58(4)$ \\
\hline \multicolumn{3}{|l|}{ Chemistries SAE } \\
\hline Glucose level & $23(2)$ & $16(I)$ \\
\hline Potassium level & $2(<1)$ & $2(<1)$ \\
\hline \multicolumn{3}{|l|}{ General SAE } \\
\hline Decreased bone density & $45(3)$ & $45(3)$ \\
\hline Hypersensitivity & $10(1)$ & $10(I)$ \\
\hline Steroid-associated changes & $2(<1)$ & $2(<1)$ \\
\hline Local glucocorticoid effects & 0 & $\mathrm{I}(<\mathrm{I})$ \\
\hline
\end{tabular}

Note: Adapted from N Engl J Med. Vestbo J, Leather D, Diar Bakerly N, et al; Salford Lung Study Investigators. Effectiveness of fluticasone furoate-vilanterol for COPD in clinical practice. 375(13):1253-1260. Copyright @ 2016 Massachusetts Medical Society. Reprinted with permission from Massachusetts Medical Society. ${ }^{36}$

Abbreviations: FF, fluticasone furoate; $\mathrm{VI}$, vilanterol; SAE, serious adverse events; $\mathrm{PRCT}$, pragmatic randomized controlled trial.

ies evaluating FF/VI. ${ }^{38}$ The $8 \%$ eCOPD reduction seen in the SLS-COPD pRCT was less than the $29 \%$ eCOPD reduction found as compared to the placebo-treated group in the large SUMMIT RCT trial with inhaled FF/VI. ${ }^{39}$ It is reassuring that the use of FF/VI in a real-world population of COPD patients was superior to usual care as prescribed by the patient's general practitioner in reducing moderate to severe exacerbations. The SLS-COPD pRCT confirmed a reduction in eCOPD as seen in multiple RCTs. The lack of an increase in serious adverse events in the SLS-COPD study with FF/VI use, particularly pneumonia, was also an important practical finding. Limitations of the SLS-COPD study include the fact that it was an open-label study with, to date, no data published on drug adherence or patient education that was given.

\section{Discussion on RCTs and combination inhalers in COPD}

The combination inhaler options for COPD maintenance have increased dramatically over the last few years, with multiple ICS/LABA and LABA/LAMA inhalers now available. ${ }^{40,41}$ The importance of combined therapy in COPD is well established. ${ }^{42,43}$ Recent large RCTs have shown efficacy of combined inhalers in the treatment of COPD. Several RCTs supporting the use of dry-powder, once-daily inhaled $\mathrm{FF} / \mathrm{VI}$ as a maintenance therapy in COPD exist. Most of 
the phase 3 RCT trials were double-blind, multicenter trials that evaluated one inhalation daily of powder FF/VI in adult patients with COPD. Some are crossover trials, but some evaluated different doses, usually against a placebo dry-powder device. ${ }^{38}$ Endpoints of the RCTs included peak flows, $\mathrm{FEV}_{1}$, and weighted $\mathrm{FEV}_{1}\left(\mathrm{wFEV}_{1}\right)$ measurements at different times and dyspnea scores in trials that lasted up to 1 year. ${ }^{38,44}$ The improvements in lung function, health status, and dyspnea scores reported and side effects seen with once-daily inhaled FF/VI in RCTs were similar to other ICS/ LABA combination inhalers in the maintenance of COPD. ${ }^{45}$ A recent large multicenter, doubled-blind RCT called the SUMMIT trial was done in 43 countries and enrolled 16,485 patients with moderate COPD and a heightened risk for cardiovascular disease. Patients were randomized to oncedaily powder FF (100 mcg), VI (25 mcg), a combination FF/VI (100/25 mcg), or placebo inhalers. ${ }^{39}$ The primary outcome was all-cause mortality. Episodes of eCOPD were another predefined endpoint. A composite of cardiovascular events metric was also recorded. The study duration was 3 years. When compared to placebo, all-cause mortality was unaffected by the use of combination FF/VI (hazard ratio [HR] 0.88 ; 95\% CI $0.74-1.0$ ) with a $12 \%$ relative reduction, $(P=0.137)$. The composite cardiovascular events measure showed no effect of FF/VI use compared to placebo (HR 0.93 ; 95\% CI $0.75-1.14) .{ }^{46}$ In addition, daily inhaled FF/VI reduced the rate of moderate/severe eCOPD by $29 \%(95 \%$ CI 22-35; $P<0.001)$ compared to placebo. ${ }^{39}$ No increase in pneumonia incidence was seen (5\% placebo; $6 \% \mathrm{FF} / \mathrm{VI}$ group; 5\% FF group; and 4\% VI group). This is particularly interesting because a meta-analysis of ICS use, alone or in combination with a LABA, in 10,150 COPD patients in 17 trials found that the use of ICS was associated with increased risk of serious pneumonia events without affecting mortality compared to controls. ${ }^{47}$ The SUMMIT RCT and the SLS-COPD pRCT provide complementary "efficacy" and "effectiveness" data on the use of inhaled FF/VI in the treatment of COPD patients.

Additional recent trials include the FLAME trial, which was a 52-week, double-blind, double-dummy, non-inferiority RCT in 1,680 COPD patients with heightened cardiovascular risk who had had at least one eCOPD during the previous year. It found that inhaled once-daily LAMA glycopyrronium (GYP; $50 \mathrm{mcg}$ ) with the LABA indacaterol (IND; $110 \mathrm{mcg}$ ) was more effective than the inhaled twice-daily ICS fluticasone proprionate (FP; $500 \mathrm{mcg}$ ) with the LABA salmeterol (SAL) in reducing the annual rate of exacerbations ( $0.98 \mathrm{vs}$ 1.19 , rate ratio, $0.83 ; 95 \% \mathrm{CI} 0.75-0.91) .{ }^{48}$ The time to first exacerbation was longer in the inhaled GLY/IND-treated group than in the inhaled FP/SAL-treated group. Another recent RCT was the LANTERN trial. This double-blind, double-dummy, parallel-group RCT in 744 COPD patients compared inhaled GYP/IND (50/110 mcg) daily to twicedaily inhaled FP/SAL (500/50) in a 26-week study. ${ }^{49}$ The LAMA/LABA combination of GYP/IND demonstrated a significant improvement in both trough $\mathrm{FEV}_{1}$ and the area under the curve of $\mathrm{FEV}_{1}$ between 0 and 4 hours after dosing. In COPD patients at high risk for exacerbations, a dry-powder once-daily inhaled triple-combination agent with FF, VI, and the LAMA umeclidinium is under development with early promising data. ${ }^{50}$

\section{The SLS real-world pragmatic RCTs - conclusion}

The pRCT SLS-asthma and -COPD studies with inhaled FF/VI offer complementary effectiveness data to traditional RCTs. If the drug effect is strong enough to show a statistically significant signal despite the real-world setting, with its challenges including drug-use adherence and multiple medical and social confounders, then it is likely to be generalizable to clinical practice. Demonstrating drug effectiveness and safety in a practical clinical setting and in a much less selected population than in a normal-efficacy RCT provides important data for the clinician. The cost of new drug approval is already prohibitively expensive. A pRCT like the SLS-asthma and -COPD trials had to be expensive, with as many as 150 GlaxoSmithKline-funded health care personnel working on the study at one time. ${ }^{25}$ Unless these trials can either replace some of the required RCTs for approval or can be done at a reasonable cost, it is unclear how the new drug-approval process can require large $\mathrm{pRCT}$ in addition to multiple, large RCTs as a routine required step in the drugapproval process. Another limitation of the pRCT is that it is easiest done in a single-community setting where a single EMR and pharmacy system exists. This potential population homogeneity is unlike a recent large FF/VI study on eCOPD that enrolled more than 16,000 patients in 43 countries insuring patient heterogeneity. ${ }^{39}$ In addition to pharmaceutical approval studies, another important role for the pRCT is in treatment guideline formation and validation. Having RCTs defining the efficacy and safety and confirming those findings in a real-world pRCT defining effectiveness would insure the appropriateness of the therapy in the formulation of disease treatment guidelines. The real-world pRCT is likely to become more common and will likely be done in large organized health care systems built around integrated 
pharmacies and EMR systems. The $\mathrm{pRCT}$ provides evidence of drug safety and effectiveness outside the ideal conditions of the classical efficacy RCT. ${ }^{51}$ When primary and secondary caregivers, pharmacies, hospitals, home nurses, and social workers are all on the same electronic record, studies could be relatively inexpensive to evaluate drug therapy or other interventions in the future in a real-world environment.

\section{Acknowledgment}

This research did not receive any funding. Specifically, the authors have had no honorarium, consulting fees, stocks, contracts, or research funding from GSK in the last 36 months.

\section{Disclosure}

The authors report no conflicts of interest in this work.

\section{References}

1. Vargesson N. Thalidomide-induced teratogenesis: history and mechanisms. Birth Defects Res C Embryo Today. 2015;105(2):140-156.

2. Fishman AP. Aminorex to fen/phen: an epidemic foretold. Circulation. 1999;99(1):156-161.

3. Volmar KE, Hutchins GM. Aortic and mitral fenfluramine-phentermine valvulopathy in 64 patients treated with anorectic agents. Arch Pathol Lab Med. 2001;125(12):1555-1561.

4. Kancherla MK, Salti HI, Mulderink TA, Parker M, Bonow RO, Mehlman DJ. Echocardiographic prevalence of mitral and/or aortic regurgitation in patients exposed to either fenfluramine-phentermine combination or to dexfenfluramine. Am J Cardiol. 1999;84(11):1335-1338.

5. Gardin JM, Schumacher D, Constantine G, Davis KD, Leung C, Reid CL. Valvular abnormalities and cardiovascular status following exposure to dexfenfluramine or phentermine/fenfluramine. JAMA. 2000;283(13):1703-1709.

6. Sachdev M, Miller WC, Ryan T, Jollis JG. Effect of fenfluraminederivative diet pills on cardiac valves: a meta-analysis of observational studies. Am Heart J. 2002;144(6):1065-1073.

7. Kramer MS, Lane DA. Aminorex, dexfenfluramine, and primary pulmonary hypertension. J Clin Epidemiol. 1998;51(4):361-364.

8. Walker AM, Langleben D, Korelitz JJ, et al. Temporal trends and drug exposures in pulmonary hypertension: an American experience. $\mathrm{Am}$ Heart J. 2006;152(3):521-526.

9. Johnston JA, Cluxton RJ Jr, Heaton PC, Guo JJ, Moomaw CJ, Eckman MH. Predictors of warfarin use among Ohio medicaid patients with new-onset nonvalvular atrial fibrillation. Arch Intern Med. 2003;163(14):1705-1710.

10. Connolly SJ, Ezekowitz MD, Yusuf S, et al; RE-LY Steering Committee and Investigators. Dabigatran versus warfarin in patients with atrial fibrillation. N Engl J Med. 2009;361(12):1139-1151.

11. Baker WL, Cios DA, Sander SD, Coleman CI. Meta-analysis to assess the quality of warfarin control in atrial fibrillation patients in the United States. J Manag Care Pharm. 2009;15(3):244-252.

12. Platt AB, Localio AR, Brensinger CM, et al. Risk factors for nonadherence to warfarin: results from the IN-RANGE study. Pharmacoepidemiol Drug Saf. 2008;17(9):853-860.

13. Kneeland PP, Fang MC. Current issues in patient adherence and persistence: focus on anticoagulants for the treatment and prevention of thromboembolism. Patient Prefer Adherence. 2010;4:51-60.

14. Sciurba F, Rennard SI. Rationale for a redundant formulary. The Hawthorne effect and the art of medicine. Am J Respir Crit Care Med. 2015;191(11):1224-1225.
15. Hagel S, Reischke J, Kesselmeier M, et al. Quantifying the hawthorne effect in hand hygiene compliance through comparing direct observation with automated hand hygiene monitoring. Infect Control Hosp Epidemiol. 2015;36(8):957-962.

16. Dal-Ré R. Could phase 3 medicine trials be tagged as pragmatic? A case study: the Salford COPD trial. J Eval Clin Pract. Epub 2017 July 7.

17. Flay BR. Efficacy and effectiveness trials (and other phases of research) in the development of health promotion programs. Prev Med. 1986;15(5):451-474.

18. Gartlehner G, Hansen RA, Nissman D, Lohr KN, Carey TS. Criteria for Distinguishing Effectiveness From Efficacy Trials in Systematic Reviews. Rockville, MD: Agency for Healthcare Research and Quality (US); 2006.

19. Tosh G, Soares-Weiser K, Adams CE. Pragmatic vs explanatory trials: the pragmascope tool to help measure differences in protocols of mental health randomized controlled trials. Dialogues Clin Neurosci. 2011;13(2):209-215.

20. Mullin R. Cost to Develop New Pharmaceutical Drug Now Exceeds \$2.5B. Scientific American: Springer Nature; 2014.

21. Yildirim O, Gottwald M, Schüler P, Michel MC. Opportunities and challenges for drug development: public-private partnerships, adaptive designs and big data. Front Pharmacol. 2016;7:461.

22. Yin G, Lam CK, Shi H. Bayesian randomized clinical trials: from fixed to adaptive design. Contemp Clin Trials. 2017;59:77-86.

23. Bent-Ennakhil N, Coste F, Xie L, et al. A real-world analysis of treatment patterns for cholinesterase inhibitors and memantine among newly-diagnosed Alzheimer's disease patients. Neurol Ther. 2017;6(1): 131-144.

24. Frieden TR. Evidence for health decision making - beyond randomized, controlled trials. $N$ Engl J Med. 2017;377(5):465-475.

25. New JP, Bakerly ND, Leather D, Woodcock A. Obtaining real-world evidence: the Salford Lung Study. Thorax. 2014;69(12):1152-1154.

26. Collier S, Harvey C, Brewster J, et al. Monitoring safety in a phase III real-world effectiveness trial: use of novel methodology in the Salford Lung Study. Pharmacoepidemiol Drug Saf. 2017;26(3):344-352.

27. Elkhenini HF, Davis KJ, Stein ND, et al. Using an electronic medical record (EMR) to conduct clinical trials: Salford Lung Study feasibility. BMC Med Inform Decis Mak. 2015;15:8.

28. Bakerly ND, Woodcock A, New JP, et al. The Salford Lung Study protocol: a pragmatic, randomised phase III real-world effectiveness trial in chronic obstructive pulmonary disease. Respir Res. 2015;16:101.

29. Syed YY. Fluticasone furoate/vilanterol: a review of its use in patients with asthma. Drugs. 2015;75(4):407-418.

30. Albertson TE, Bullick SW, Schivo M, Sutter ME. Spotlight on fluticasone furoate/vilanterol trifenatate for the once-daily treatment of asthma: design, development and place in therapy. Drug Des Devel Ther. 2016;10:4047-4060.

31. Albertson TE, Richards JR, Zeki AA. The combination of fluticasone furoate and vilanterol trifenatate in the management of asthma: clinical trial evidence and experience. Ther Adv Respir Dis. 2016;10(1): $43-56$.

32. Tan LD, Chan AL, Albertson TE. New combination treatments in the management of asthma: focus on fluticasone/vilanterol. J Asthma Allergy. 2014;7:77-83.

33. Calzetta L, Rinaldi B, Cazzola M, Matera MG. Pharmacodynamic and pharmacokinetic assessment of fluticasone furoate + vilanterol for the treatment of asthma. Expert Opin Drug Metab Toxicol. 2016;12(7):813-822.

34. Dwan K, Milan SJ, Bax L, Walters N, Powell C. Vilanterol and fluticasone furoate for asthma. Cochrane Database Syst Rev. 2016;9:CD010758.

35. Woodcock A, Bakerly ND, New JP, et al. The Salford Lung Study protocol: a pragmatic, randomised phase III real-world effectiveness trial in asthma. BMC Pulm Med. 2015;15:160.

36. Vestbo J, Leather D, Diar Bakerly N, et al; Salford Lung Study Investigators. Effectiveness of fluticasone furoate-vilanterol for COPD in clinical practice. $N$ Engl J Med. 2016;375(13):1253-1260. 
37. ClinicalTrials.gov. A randomised effectiveness study comparing fluticasone furoate (FF, GW685698)/vilanterol (VI, GW642444) with standard treatment in chronic obstructive pulmonary disease (COPD). 2017. Available from: https://clinicaltrials.gov/ct2/show/NCT01551758. Accessed July 27, 2017.

38. McKeage K. Fluticasone furoate/vilanterol: a review of its use in chronic obstructive pulmonary disease. Drugs. 2014;74(13):1509-1522.

39. Martinez FJ, Vestbo J, Anderson JA, et al; SUMMIT Investigators. Effect of fluticasone furoate and vilanterol on exacerbations of chronic obstructive pulmonary disease in patients with moderate airflow obstruction. Am J Respir Crit Care Med. 2017;195(7):881-888.

40. Kardos P, Worsley S, Singh D, Román-Rodríguez M, Newby DE, Müllerová H. Randomized controlled trials and real-world observational studies in evaluating cardiovascular safety of inhaled bronchodilator therapy in COPD. Int J Chron Obstruct Pulmon Dis. 2016;11:2885-2895.

41. Schivo M, Albertson TE, Haczku A, et al. Paradigms in chronic obstructive pulmonary disease: phenotypes, immunobiology, and therapy with a focus on vascular disease. J Investig Med. 2017;65(6):953-963.

42. Nannini LJ, Poole P, Milan SJ, Holmes R, Normansell R. Combined corticosteroid and long-acting beta ${ }_{2}$-agonist in one inhaler versus placebo for chronic obstructive pulmonary disease. Cochrane Database Syst Rev. 2013;(11):CD003794.

43. Kew KM, Dias S, Cates CJ. Long-acting inhaled therapy (beta-agonists, anticholinergics and steroids) for COPD: a network meta-analysis. Cochrane Database Syst Rev. 2014;(3):CD010844.
44. Matera MG, Capuano A, Cazzola M. Fluticasone furoate and vilanterol inhalation powder for the treatment of chronic obstructive pulmonary disease. Expert Rev Respir Med. 2015;9(1):5-12.

45. Bateman ED, Mahler DA, Vogelmeier CF, Wedzicha JA, Patalano F, Banerji D. Recent advances in COPD disease management with fixed-dose long-acting combination therapies. Expert Rev Respir Med. 2014;8(3):357-379.

46. Vestbo J, Anderson JA, Brook RD, et al; SUMMIT Investigators. Fluticasone furoate and vilanterol and survival in chronic obstructive pulmonary disease with heightened cardiovascular risk (SUMMIT): a double-blind randomised controlled trial. Lancet. 2016;387(10030):1817-1826.

47. Kew KM, Seniukovich A. Inhaled steroids and risk of pneumonia for chronic obstructive pulmonary disease. Cochrane Database Syst Rev. 2014;(3):CD010115.

48. Wedzicha JA, Banerji D, Chapman KR, et al; FLAME Investigators. Indacaterol-glycopyrronium versus salmeterol-fluticasone for COPD. N Engl J Med. 2016;374(23):2222-2234.

49. Zhong N, Wang C, Zhou X, et al; LANTERN Investigators. LANTERN: a randomized study of QVA149 versus salmeterol/fluticasone combination in patients with COPD. Int J Chron Obstruct Pulmon Dis. 2015;10:1015-1026.

50. Lal C, Strange C. Spotlight on fluticasone furoate/umeclidinium/ vilanterol in COPD: design, development, and potential place in therapy. Int J Chron Obstruct Pulmon Dis. 2016;12:135-140. eCollection 2017.

51. Barnish MS, Turner S. The value of pragmatic and observational studies in health care and public health. Pragmat Obs Res. 2017;8:49-55.
Pragmatic and Observational Research

\section{Publish your work in this journal}

Pragmatic and Observational Research is an international, peer-reviewed, open access journal that publishes data from studies designed to reflect more closely medical interventions in real-world clinical practice compared with classical randomized controlled trials (RCTs). The manuscript management system is completely online and includes a very quick and fair peer-review

\section{Dovepress}

system. Visit http://www.dovepress.com/testimonials.php to read real quotes from published authors.

Submit your manuscript here: https://www.dovepress.com/pragmatic-and-observational-research-journal 